JGG 2021;69:110-113

doi: $10.36150 / 2499-6564-N 001$

\title{
Safety and tolerability of intravenous ferric carboxymaltose in the oldest old patients: a prospective cohort study in a University Italian Geriatrics Department
}

\author{
Luca Tagliafico ${ }^{1,2}$, Maria Nives Parodi ${ }^{3}$, Patrizio Odetti ${ }^{1,2}$, \\ Alessio Nencioni ${ }^{1,2}$, Fiammetta Monacelli ${ }^{1,2}$ \\ ${ }^{1}$ Geriatrics Clinic, Department of Internal Medicine and Medical Specialties (DIMI), University of \\ Genoa, Italy; ${ }^{2}$ IRCCS Ospedale Policlinico San Martino, Genoa, Italy; ${ }^{3}$ Medicine 2, San Paolo \\ Hospital Savona, Italy
}

Received: June 30, 2020

Accepted: February 22, 2021

\section{Correspondence}

Fiammetta Monacelli

Geriatrics Clinic, Department of Internal Medicine and Medical Specialties (DIMI), University of Genoa, viale Benedetto XV 6, 16132 Genoa, Italy E-mail: fiammetta.Monacelli@unige.it

\section{Conflict of interest}

The Authors declare no conflict of interest

How to cite this article: Tagliafico $\mathrm{L}, \mathrm{Pa}$ rodi MN, Odetti P, et al. Safety and tolerability of intravenous ferric carboxymaltose in the oldest old patients: a prospective cohort study in a University Italian Geriatrics Department. Journal of Gerontology and Geriatrics 2021;69:110-113. https:// doi.org/10.36150/2499-6564-N001

C Copyright by Società Italiana di Gerontologia e Geriatria (SIGG)

\section{(c) (1)(9) (}

\section{OPEN ACCESS}

This is an open access article distributed in accordance with the CC-BY-NC-ND (Creative Commons Attribution-NonCommercial-NoDerivatives 4.0 International) license. The article can be used by giving appropriate credit and mentioning the license, but only for non-commercial purposes and only in the original version. For further information: https://creativecommons.org/licenses/by-nc-nd/4.0/deed.en
Background \& aims. Anemia is common in older adults and it is associated with relevant complications. Although anemia is often multifactorial in origin and iron deficiency is considered a key relevant causative factor. The first therapeutic option is oral iron supplementation, but it is frequently characterized by adverse effects and overall poor efficacy. So far, intravenous (i.v.) iron formulations may serve as alternative treatment options and, in particular, Ferric carboxymaltose (FCM), showed to be safe and effective in older patients. We aimed to assess the safety and tolerability of FCM in real world hospitalized frail oldest old patients. Methods. This is an observational prospective study on 25 old age patients with iron deficiency anemia (IDA), admitted between July 2019 and November 2019 to the Geriatric Clinical ward of the IRCCS Policlinico San Martino, Genoa, Italy and treated with i.v. FCM. The incidence, probability and severity of adverse drug reactions (ADR) were reported along with the clinical response in term of mean Haemoglobin $(\mathrm{Hb})$ increase after one week from the drug administration.

Results. $72 \%$ of patients were oldest old with IDA and the clinical phenotype was characterized by multimorbidity and disability. The mean dose of i.v. FCM was $1160.0 \pm 313.6 \mathrm{mg}$. FCM resulted safe therapeutic option with overall good tolerability. Additionally, a significant clinical improvement in the mean $\mathrm{Hb}$ level was observed.

Conclusions. These findings moved a step in the recommendation of i.v. iron supplementation as a preferable route in oldest old, serving as a potential platform for future randomized clinical studies.

Key words: ferric carboxymaltose, anemia, hospitalized old patients

\section{INTRODUCTION}

Anemia is a common clinical condition in old age patients, with a prevalence that ranges from 3 to $25 \%$ in community dwellings, raising approximately to $31-50 \%$ in nursing homes and to $40-72 \%$ in hospitals ${ }^{1}$. Growing evidence indicates that it is associated with increased disability, poorer physical performance, sarcopenia ${ }^{2}$ and higher risk of mortality and re-hospitalization ${ }^{3}$. Although it is observed a multifactorial origin for anemia, iron deficiency anemia (IDA) and anemia of inflammation (Al) are considered the most prevalent 
subtypes of anemia in elders ${ }^{4-5}$ with an absolute or functional iron deficiency, respectively, that in the latter case may be responsible for the process of "inflammaging", an age-related low-grade chronic inflammation ${ }^{6}$. Additionally, multimorbidity and polypharmacy may contribute to nutritional deficiencies with absolute or partial iron depletion, further entangling the true nature of anemia, especially in the oldest old patients.

Although oral iron supplementations are considered the first line treatment for IDA in older adults, the reduction of iron bowel absorption due to increased hepcidin levels, as a result of chronic inflammation ${ }^{7}$ and the poor gastrointestinal tolerability to long-term therapeutic regimens deeply affect its efficacy and effectiveness along with patients' compliance over time ${ }^{5}$. Indeed, the intravenous (i.v.) iron supplementation may represent an alternative treatment option ${ }^{8}$, and in particular, Ferric carboxymaltose (FCM, Ferinject, Vifor (International) Inc., St. Gallen, Switzerland) is an iron parenteral formulation of non-dextran-containing complex that allows for the administration of a large replenishment dose ( $\leq 1,000 \mathrm{mg}$ of iron) over a short infusion period (15-30 minutes) ${ }^{9}$. So far, scant evidence showed that FCM is a well tolerated and an effective treatment option in geriatric patients ${ }^{10}$. Given this scenario, here we aimed at assessing the safety and tolerability of FCM in a cohort of oldest old hospitalized patients with IDA.

\section{PATIENTS AND METHODS}

This is an observational prospective study on 25 consecutive old age patients ( $\geq 75$ years), admitted between July and November 2019 at the Geriatric Clinic of the IRCCS Policlinico San Martino, Genoa, Italy. Inclusion criteria were age $\geq 75$ years, $\mathrm{Hb}$ levels below $12 \mathrm{~g} / \mathrm{dL}$ for women and $13 \mathrm{~g} / \mathrm{dL}$ for men with a transferrin saturation $<20 \%$ and signed written informed consent. Exclusion criteria were age $<75$ years, clinical instability, acute systemic infection, end stage diseases in palliative care, advanced dementia, the diagnosis of anemia with a transferrin saturation $>20 \%$. The study was approved by the local ethical committee.

Demographic data were collected at baseline and all patients received a geriatric clinical assessment, including functional status (Barthel index) ${ }^{11}$ and multimorbidity [Cumulative IIIness Rating Scale (CIRS)] ${ }^{12}$. Baseline biochemical plasmatic assessment for Iron $(\mu \mathrm{g} / \mathrm{dL})$, Transferrin (g/L), Transferrin saturation (\%), Ferritin (ng/ $\mathrm{ml}$ ) and $\mathrm{Hb}$ levels $(\mathrm{g} / \mathrm{dL})$ at baseline and, respectively, after two weeks were collected.

The dosage of FCM for each patient was calculated according to the body weight of the patient and the haemoglobin level (1000 mg with a body weight $<70 \mathrm{~kg}$ and $\mathrm{Hb}>10 \mathrm{~g} / \mathrm{dL}, 1500 \mathrm{mg}$ with a body weight $>70 \mathrm{~kg}$ and $\mathrm{a} \mathrm{Hb}>10 \mathrm{~g} / \mathrm{dL}$ or with a body weight $<70 \mathrm{~kg}$ and $\mathrm{Hb}<10 \mathrm{~g} / \mathrm{dL}$ and $2000 \mathrm{mg}$ with a body weight $>70 \mathrm{~kg}$ and $\mathrm{Hb}<10 \mathrm{~g} / \mathrm{dL}$ ). The maximum dosage for each i.v. administration was $1000 \mathrm{mg}$ with a timely administration of one week between each administration.

Safety and tolerability of FCM were assessed by virtue of the incidence and severity of adverse drug reaction (ADR), according to ADR Severity Assessment Scale ${ }^{13}$ and ADR probability scale of Naranjo ${ }^{14}$, respectively. Routine physical parameters and routine clinical laboratory were documented.

The efficacy of FCM was also documented by changes in $\mathrm{Hb}$ levels after one week from the last administration of the drug. Treatment responders were defined as those patients with an $\mathrm{Hb}$ increase $>1 \mathrm{~g} / \mathrm{dl}$ after one week from the last administration of FCM.

\section{Statistical analyses}

Data are expressed with arithmetical means and standard deviations. The comparison between two groups was performed with the non-parametric Mann-Whitney $U$ test. A P value $<0.05$ was considered statistically significant. Graph Pad 7.0 version was used for the statistical analysis.

\section{RESULTS}

Patients' clinical characteristics are illustrated in Table I, while iron status is reported in Table II.

Patients' mean age was $87.7 \pm 6.0$ years with $72 \%$ of oldest old patients and 15 females and 10 males, respectively. Patient's clinical phenotype was characterized by disability and multimorbidity (Barthel index $23.2 \pm 3.6$; CIRS with severity index $2.1 \pm 0.3$ and severe comorbidity $5.0 \pm 1.2$ ).

Required mean cumulative dose of i.v. FCM was $1160.0 \pm 313.6 \mathrm{mg}$ and it was administered in one

Table I. Patients' clinical characteristics.

\begin{tabular}{|l|c|}
\hline Age (years) & $87.7 \pm 6.0$ \\
\hline Gender & 10 male and 15 female \\
\hline Infectious diseases & 7 \\
\hline Neoplasm & 7 \\
\hline Cardiovascular disease & 2 \\
\hline Digestive tract disease & 2 \\
\hline Disturbance of gait and mobility & 4 \\
\hline Fractures & $2.1 \pm 0.3$ (severity) \\
\hline CIRS & $23.2 \pm 23.6$ \\
\hline Barthel index & and $5.0 \pm 1.2$ (comorbidity) \\
\hline
\end{tabular}


Table II. Baseline iron-status of the patients.

\begin{tabular}{|l|c|c|}
\hline & Mean & $\begin{array}{c}\text { Standard } \\
\text { deviation }\end{array}$ \\
\hline Iron $(\mu \mathrm{g} / \mathrm{dL})$ & 26.3 & 7.4 \\
\hline Transferrin $(\mathrm{g} / \mathrm{L})$ & 1.4 & 0.3 \\
\hline Transferrin saturation $(\%)$ & 13.8 & 4.2 \\
\hline Ferritin $(\mathrm{ng} / \mathrm{ml})$ & 327.0 & 231.9 \\
\hline
\end{tabular}

Table III. Dosage of ferric carboxymaltose.

\begin{tabular}{|l|c|c|}
\hline & Mean & $\begin{array}{c}\text { Standard } \\
\text { deviation }\end{array}$ \\
\hline I dose FCM (25 patients, $\mathrm{mg})$ & $960.0(25)$ & 138.4 \\
\hline II dose FCM (8 patients, $\mathrm{mg})$ & $625.0(8)$ & 231.5 \\
\hline Mean dose FCM per patient $(\mathrm{mg})$ & 1160.0 & 313.6 \\
\hline
\end{tabular}

or two i.v. infusion (17 patients received a single dose administration and 8 patients received two i.v. administration). Further details of iron supplementation are reported in Table III.

\section{SAFETY AND TOLERABILITY}

Intravenous FCM was safe and well tolerated in our cohort of hospitalized and very old patients. Namely, one patient (8\%) had mild grade ADR with transient thoracic pain after the i.v. FCM administration without any troponin rise and immediate clinical resolution (level of severity 1 , Probable according to ADR probability scale) whereas another patient had a rheumatoid arthritis flare (level of severity 4, Possible according to ADR probability scale $A D R)$, respectively, that, however, was of short duration and it did not required any further therapeutic adjustment (summary of the ADR is reported in the Table IV).

\section{EFFICACY}

Mean $\mathrm{Hb}$ levels at baseline were $9.5 \pm 1.1 \mathrm{mg} / \mathrm{dL}$ and after one week from the last administration of FCM the mean $\mathrm{Hb}$ level was $10.5 \pm 1.0 \mathrm{mg} / \mathrm{dL}$. The mean period of evaluation of $\mathrm{Hb}$ for each patients from baseline to one

Table IV. Adverse events related to ferric carboxymaltose.

\begin{tabular}{|l|c|c|}
\hline Body system & $\begin{array}{c}\text { Number } \\
\text { of ADR }\end{array}$ & $\begin{array}{c}\text { Mean } \\
\text { dosage }\end{array}$ \\
\hline Cardiovascular & 0 & N/A \\
\hline Hemic and lymphatic & 0 & N/A \\
\hline Infection & 0 & N/A \\
\hline Metabolic and nutritional & 0 & $\mathrm{~N} / \mathrm{A}$ \\
\hline Muscoloskeletal & 1 & $1000 \mathrm{mg}$ \\
\hline Nervous system & 1 & $1000 \mathrm{mg}$ \\
\hline Respiratory & 0 & $\mathrm{~N} / \mathrm{A}$ \\
\hline Skin and appendages & 0 & $\mathrm{~N} / \mathrm{A}$ \\
\hline
\end{tabular}

week after the last administration of FCM was $9.2 \pm 3.3$ days. The mean $\mathrm{Hb}$ increase was $0.9 \pm 1.0 \mathrm{mg} / \mathrm{dL}$ and the difference of $\mathrm{Hb}$ level from baseline is statistically significant $(N=25 ; U=233 ; p<0.03) .13$ patients $(52 \%)$ had a $\mathrm{Hb}$ increase $>1 \mathrm{~g} / \mathrm{dl}$ after FCM and they were considered as responder according to the criteria previously mentioned. 9 patients (36\%) had a Hb increase $<1 \mathrm{~g} /$ dl and 3 patients (12\%) didn't respond to FCM therapy.

\section{DISCUSSION}

So far, there is scant evidence on the safety, tolerability end effectiveness of FCM in old age patients and, in particular, the inclusion of frail and highly vulnerable oldest old patients is urgently needed to fill a gap of knowledge in the light of their clinical complexity. Current main clinical indications of i.v. FCM in IDA rely on patients' poor tolerability, uncompliance to oral iron regimens and/or lack of effectiveness. Although it is growingly acknowledged that clinicians are more in the position of treating IDA in older adults and that this highly vulnerable population is more likely to experience uncompliance to oral iron regimens, with poorer clinical outcomes ${ }^{5}$ the need to optimize care for these subjects seems to be greatly underestimated up to date. In line with these notions, the investigation of the tolerability profile of an i.v. iron supplementation such as FCM is of key relevance and may point to assess the clinical to benefit ratio with potential clinical implications for the oldest old.

To the best of our knowledge this is among the few reports to underscore the safety and good tolerability of iv FCM in real world hospitalized oldest old patients and the present original findings moved a step forwards in this understanding with the ultimate goal to provide more information about how to best implement IDA treatment in frail, very old and complex The existing literature is scant and heterogenous in terms of selected population and clinical outcomes so that the overall clinical benefit of iv FCM intervention is far from being clearly demonstrated. In line with that, Rohrig G. et al showed that FCM has a good tolerability profile in geriatric patients (mean age of 76.9 years) with no reported severe adverse reactions ${ }^{10}$. Similarly, Simon D. Roger et al in their open-label, multicenter, prospective study of non-dialysis-dependent CKD old age patients showed that i.v. FCM was a safe therapeutic option and no substantial difference was observed between oral iron therapy and FCM (the incidence of one or more adverse events was 91.0, 100.0 and 105.0 per 100 patient-years in the high ferritin FCM, low ferritin FCM and oral iron groups, respectively) ${ }^{15}$.

Although this was a secondary aim of the study, the results showed a significant mean $\mathrm{Hb}$ increase, addressing FMC 


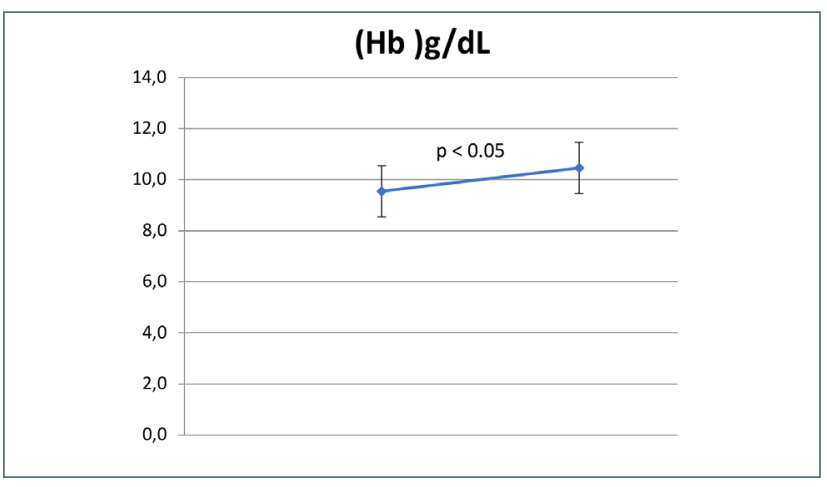

Figure 1. Mean haemoglobin level before and after the treatment with ferric carboxymaltose (Wilcoxon signed-rank test was used for statistical evaluation).

as an efficacy iron repleshinement alternative therapy in old age frail patients. In addition, the response efficacy was obtained despite baseline ferritin levels of $327.0 \pm 231.9$ $\mu \mathrm{g} / \mathrm{L}$ that could support the notion that ferritin is an unreliable marker of iron deficiency in the older and frailer patients. In line with this notion, as previously reported, ferritin seems not to accurately predict the clinical response to i.v. martial therapy in old age patients ${ }^{16}$.

The main limitations of this study are the small sample size, the limited observational period, the monocentric hospital setting that may affect the generalization of the findings. Moreover, the lack of the longitudinal assessment of the physical performance, sarcopenia and functional status may also represent a limitation, but they are part of an ongoing study. The strengths rely on its prospective nature, the real world oldest old hospitalized patients with frail clinical phenotype.

\section{CONCLUSIONS}

Eventually, this study, although preliminary in nature, moved a step forwards in the recommendation of i.v. iron supplementation as a preferable route in a real world oldest old population, that may serve as platform for randomized clinical studies. Future studies are needed to evaluate the impact of FCM on a consistent sample of very old age patients and related long-term clinical outcomes, including the impact on oldest old patients' disability, hospitalization rate and mortality.

\section{References}

1 Gaskell H, Derry S, Moore R, et al. Prevalence of anaemia in older persons: systematic review. BMC Geriatr 2008;8:1. https://doi.org/10.1186/1471-2318-8-1

2 Penninx BW, Pahor M, Cesari M, et al. Anemia is associated with disability and decreased physical performance and muscle strength in the elderly. J Am Geriatr Soc 2004;52:71924. https://doi.org/10.1111/j.1532-5415.2004.52208.x

3 Penninx BW JH, Pahor M, Woodman RC, et al. Anemia in old age is associated with increased mortality and hospitalization. J Gerontol A Biol Sci Med Sci 2006;61:474-9. https://doi.org/10.1093/gerona/61.5.474

4 Artz AS, Thirman MJ. Unexplained anemia predominates despite an intensive evaluation in a racially diverse cohort of older adults from a referral anemia clinic. J Gerontol A Biol Sci Med Sci 2011;66:925-32. https://doi.org/10.1093/gerona/glr090

5 Busti F, Campostrini N, Martinelli N, et al. Iron deficiency in the elderly population, revisited in the hepcidin era. Front Pharmacol 2014;5:83. https://doi.org/10.3389/ fphar.2014.00083

6 Paudel S, Sharma P, Puri N. Immunosenescence, Inflammaging, and their Implications for cancer and anemia. In: Rath P, Eds. Models, molecules and mechanisms in biogerontology. Singapore: Springer 2019. https://doi. org/10.1007/978-981-13-3585-3_14

7 Goodnough LT, Schrier SL, Evaluation and management of anemia in the elderly. Am J Hematol 2014;89:88-96. https://doi.org/10.1002/ajh.23598

8 Auerbach M, Goodnough LT, Shander A. Iron: the new advances in therapy. Best Pract Res Clin Anaesthesiol 2013;27:131-40. https://doi.org/10.1016/j.bpa.2012.12.001

9 Moore RA, Gaskell H, Rose P, et al. Meta-analysis of efficacy and safety of intravenous ferric carboxymaltose (Ferinject) from clinical trial reports and published trial data. BMC Blood Disord 2011;11:4. https://doi.org/10.1186/1471-2326-11-4

10 Röhrig G, Steinmetz T, Stein J, et al., Efficacy and tolerability of ferric carboxymaltose in geriatric patients with anemia. Data from three non-interventional studies. MMW Fortschr Med 2014;156(Suppl 2):48-53. https://doi. org/10.1155/2017/3106890

11 Mahoney FI, Barthel DW. Functional evaluation: the Barthel index. Md State Med J 1965;14:61-5.

12 Linn BS, Linn MW, Gurel L, Cumulative illness rating scale. J Am Geriatr Soc 1968;16:622-6. https://doi. org/10.1111/j.1532-5415.1968.tb02103.x

13 Hartwig SC, Siegel J, Schneider PJ. Preventability and severity assessment in reporting adverse drug reactions. Am J Hosp Pharm 1992;49:2229-32.

14 Naranjo CA, Busto U, Sellers EM, et al. A method for estimating the probability of adverse drug reactions. Clin Pharmacol Ther 1981;30:239-45. https://doi.org/10.1038/clpt.1981.154

15 Roger SD, Gaillard CA, Bock AH, et al. Safety of intravenous ferric carboxymaltose versus oral iron in patients with nondialysis-dependent CKD: an analysis of the 1-year FIND-CKD trial. Nephrol Dial Transplant 2017;32:1530-9. https://doi.org/10.1093/ndt/gfw264.

16 Bach M, Geisel T, Martin J, et al. Efficacy and safety of intravenous ferric carboxymaltose in geriatric inpatients at a German tertiary university teaching hospital: a retrospective observational cohort study of clinical practice. Anemia 2015;2015:647930. https://doi. org/10.1155/2015/647930 